\title{
Comparative Genomics to Develop a Specific Multiplex PCR Assay for Detection of Clavibacter michiganensis
}

\author{
Shree P. Thapa, ${ }^{1}$ Michael O’Leary, ${ }^{1}$ Marie-Agnès Jacques, ${ }^{2}$ Robert L. Gilbertson, ${ }^{1}$ and Gitta Coaker ${ }^{1, \dagger}$ \\ ${ }^{1}$ Department of Plant Pathology, University of California, Davis, CA, U.S.A. \\ 2 IRHS, Agrocampus-Ouest, INRA, Université d'Angers, SFR 4207 Quasav, Beaucouzé, France \\ Accepted for publication 26 November 2019.
}

ABSTRACT

\begin{abstract}
Clavibacter michiganensis is a Gram-positive bacterial pathogen that proliferates in the xylem vessels of tomato, causing bacterial wilt and canker symptoms. Accurate detection is a crucial step in confirming outbreaks of bacterial canker and developing management strategies. A major problem with existing detection methods are false-positive and -negative results. Here, we report the use of comparative genomics of 37 diverse Clavibacter strains, including 21 strains sequenced in this study, to identify specific sequences that are $C$. michiganensis detection targets. Genome-wide phylogenic analyses revealed additional diversity within the genus Clavibacter. Pathogenic C. michiganensis strains varied in plasmid composition, highlighting the need for detection methods based on chromosomal targets. We utilized sequences of $C$. michiganensisspecific loci to develop a multiplex PCR-based diagnostic platform using
\end{abstract}

two C. michiganensis chromosomal genes (rhuM and tomA) and an internal control amplifying both bacterial and plant DNA (16s ribosomal RNA). The multiplex PCR assay specifically detected $C$. michiganensis strains from a panel of 110 additional bacteria, including other Clavibacter spp. and bacterial pathogens of tomato. The assay was adapted to detect the presence of $C$. michiganensis in seed and tomato plant materials with high sensitivity and specificity. In conclusion, the described method represents a robust, specific tool for detection of $C$. michiganensis in tomato seed and infected plants.

Keywords: bacteriology, Clavibacter michiganensis, comparative genomics, diagnostic, disease control and pest management, multiplex PCR, techniques, tomato
Clavibacter spp. are xylem colonizing Gram-positive bacteria that can infect both monocots and dicots. Multiple Clavibacter subspecies have been recently elevated to the species level based on average nucleotide identities derived from whole-genome analyses and digital DNA-DNA hybridization (Li et al. 2018). Clavibacter michiganensis causes bacterial canker and is one of the most important bacterial diseases of tomato (de León et al. 2011; Mansfield et al. 2012). C. michiganensis gains entry into the plant through contaminated seed, wounds, broken trichomes, or hydathodes, and then proliferates in xylem vessels (Eichenlaub et al. 2006; Sen et al. 2015). Systemic infection results in unilateral leaf wilting, necrosis of the entire plant, necrosis of stems and petioles, as well as formation of cankers (de León et al. 2011). C. michiganensis can also form localized infections, resulting in fruit-spotting "bird's eye" and blister-like spots on vegetative tissues (de León et al. 2011).

Bacterial canker can cause substantial losses in greenhouse and field production systems. Since the first report of the disease in Michigan in 1910, it has spread throughout the world (Smith 1910). The economic threat and the challenges to manage this disease have led to the inclusion of this pathogen as a quarantine agent in Europe, Asia, Africa, and the Caribbean (Anonymous 2000; Eichenlaub and Gartemann 2011). Despite the importance of this disease, there

${ }^{\dagger}$ Corresponding author: G. Coaker; glcoaker@ucdavis.edu

Funding: G. Coaker, S. Thapa, and R. L. Gilbertson were supported by grants from the California Tomato Research Board awarded to G. Coaker and R. L. Gilbertson (091). G. Coaker and S. Thapa were supported by a grant from United States Department of Agriculture-National Institute of Food and Agriculture (201567013-23082, awarded to G. Coaker) and a grant awarded by the California Department of Food and Agriculture (17-0275-047-SC).

*The $e$-Xtra logo stands for "electronic extra" and indicates that four supplementary figures and three supplementary tables are published online.

The author(s) declare no conflict of interest.

(c) 2020 The American Phytopathological Society currently are no resistant commercial cultivars or effective chemical control strategies. At present, control and management of this disease rely primarily on the use of clean seed, healthy transplant practices, sanitation, and crop rotation.

Effective disease management also requires precise, reliable, and sensitive detection methods. Historically, methods are based on semiselective media followed by pathogenicity tests (Fatmi and Schaad 2002; Fatmi et al. 2017). These diagnostic assays are expensive, require laboratory and greenhouse facilities, and are unsuitable for large-scale screening. Current C. michiganensis detection strategies mainly utilize serological (Franken et al. 1993) or PCR-based methods, with primers targeting different loci, often followed by bacterial isolation on semiselective media (Dreier et al. 1995; Kaneshiro et al. 2006; Louws et al. 1998; Milijašević-Marčić et al. 2012). However, the current serological techniques such as enzyme-linked immunosorbent assay and immunostrips are not reliable due to their cross reaction with other Clavibacter spp. (Dreier et al. 1995; Franken et al. 1993; Jacques et al. 2012).

The presence of closely related Clavibacter endophytes in tomato complicates precise detection of $C$. michiganensis, making it difficult to differentiate pathogenic C. michiganensis from other Clavibacter spp. Nonpathogenic Clavibacter spp. have been frequently found associated with tomato plants and seed (Jacques et al. 2012; Thapa et al. 2017; Yasuhara-Bell and Alvarez 2015; Zaluga et al. 2013). Furthermore, analyses of $C$. michiganensis strains collected from diverse geographical origins have revealed considerable genetic diversity, particularly with respect to plasmid composition, plasmid number, and the presence or absence of putative chromosomally encoded pathogenicity genes (Jacques et al. 2012; Milijašević-Marčić et al. 2012; Tancos et al. 2015; Thapa et al. 2017). The presence of endophytic Clavibacter spp. in tomato and the diversity in $C$. michiganensis highlights the need for a rapid, specific, and accurate method for detecting $C$. michiganensis from seed, plants, and other substrates.

PCR is rapid and highly sensitive and can be specific for identification of bacterial pathogens (McNally et al. 2016; Schaad 
and Frederick 2002; Vincelli and Tisserat 2008). Several pairs of primers have been designed for detecting $C$. michiganensis (Alvarez et al. 2005; Kaneshiro et al. 2006; Kleitman et al. 2008; Santos et al. 1997). However, most of these primers target genes present in plasmids (pCM1 and $\mathrm{pCM} 2$ ) and the chp/tomA pathogenicity island based on the reference strain NCPPB382 (Alvarez et al. 2005; Kaneshiro et al. 2006; Kleitman et al. 2008). False-positive and -negative results have been reported with most primers, and different $C$. michiganensis strains can possess variable plasmid components yet retain similar virulence (Alvarez et al. 2005; Kleitman et al. 2008; Louws et al. 1998; Tancos et al. 2015; Thapa et al. 2017). Therefore, there is a need for a robust diagnostic assay for $C$. michiganensis capable of targeting multiple genes that can differentiate $C$. michiganensis from other Clavibacter spp. and bacterial pathogens associated with tomato.

Multiplex PCR (mPCR) can be used to amplify multiple genetic loci, facilitating detection of several targets in a single pathogen (Bertolini et al. 2003; Ozdemir 2009; Thapa et al. 2012, 2013). Here, we used comparative genomics to analyze a wide range of strains representing the genus Clavibacter. This analysis revealed diversity among $C$. michiganensis strains, including multiple subgroups and variable plasmid components. Genome analyses were used to identify highly conserved mPCR targets within C. michiganensis strains. We have also validated the specificity and sensitivity of this assay on vegetative and seed samples using diverse $C$. michiganensis strains, including those collected from a recent outbreak in California.

\section{MATERIALS AND METHODS}

Bacterial strains and DNA extraction. The bacterial strains used in this study are listed in Supplementary Table S1. C. michiganensis strains were grown in tryptone broth with yeast (TBY) and on D2 semiselective media at $28^{\circ} \mathrm{C}$ (Kirchner et al. 2001). For DNA extraction, overnight cultures were grown in TBY broth at $28^{\circ} \mathrm{C}$ on a rotary shaker at $200 \mathrm{rpm}$. DNA was extracted from infected plant materials or bacterial cultures for PCR using either a crude lysis method or cetyltrimethylammonium bromide (CTAB) purification (Murray and Thompson 1980). For the lysis method, $100 \mathrm{mg}$ of plant material or bacterial cells was resuspended in extraction buffer $\left(\mathrm{Na}_{2} \mathrm{HPO}_{4}\right.$ at $7.75 \mathrm{~g} / \mathrm{liter}, \mathrm{KH}_{2} \mathrm{PO}_{4}$ at $1.65 \mathrm{~g} / \mathrm{liter}$, and Tween 20 at $0.2 \mathrm{ml} /$ liter). The supernatant was then added to cell lysis buffer ( $3 \%$ sodium dodecyl sulfate, $50 \mu \mathrm{M}$ Tris, and $10 \%$ sucrose) and incubated at $100^{\circ} \mathrm{C}$ in heat block for $15 \mathrm{~min}$. The samples were centrifuged at $11,000 \times g$ for $5 \mathrm{~min}$. The supernatant was transferred into new Eppendorf tubes. DNA was precipitated with $2 \times$ volume of $100 \%$ ethanol and centrifuged at $11,000 \times g$ for $5 \mathrm{~min}$, and the supernatant was discarded. The pellet was then washed with $70 \%$ ethanol, air dried, mixed in distilled $\mathrm{H}_{2} \mathrm{O}\left(\mathrm{dH}_{2} \mathrm{O}\right)$, and used for mPCR analyses. CTAB DNA extraction was performed as previously described (Murray and Thompson 1980).

Genome sequencing, assembly, and annotation. $C$. michiganensis strains sequenced in the present study are shown in Table 1. Total genomic DNA was isolated with the Promega Wizard Genomic DNA Purification Kit. For library construction for the Illumina platform, genomic DNA was sheared with a Covaris E220 sonicator, followed by end repair and phosphorylation. Fragmented DNA was used to construct paired-end libraries. Libraries were checked for size with a High Sensitivity DNA Kit (Agilent) in the Bioanalyzer 2100, with an expected average size of $250 \mathrm{bp}$. Libraries were pooled and sequenced with paired-end reads on the HiSeq 2500 system (Illumina). Genome sequencing was performed at the University of California-Davis DNATechnologies Core Facility. Genomes sequenced on Illumina were de novo assembled with the SPAdes (Bankevich et al. 2012). The draft genomes were annotated with Prokka and the NCBI Prokaryotic Genome Annotation Pipeline (Seemann 2014; Tatusova et al. 2016).
Phylogenetic analyses. Orthologous genes of Clavibacter strains were predicted with the OrthoMCL pipeline (Li et al. 2003). All-versus-all BLASTN ( $E$ value $<1 \times 10^{-5}$, alignment coverage $>50 \%$ ) comparison of all gene sequences for each species was performed, and orthologous genes were clustered with OrthoMCL (Li et al. 2003). The normalized scores were fed into the MCL algorithm to classify the genes into predicted orthologous gene families with a default inflation parameter of 1.5. We performed multiple alignments of gene sequences with Prank (Loytynoja and Goldman 2005). Alignments were concatenated by FASconCAT, yielding a gene supermatrix (Kück and Meusemann 2010). A maximum-likelihood approach was used to reconstruct the phylogenetic tree using RAxML software (Stamatakis 2006). Bootstrapping was performed with 1,000 replicates. The resulting phylogeny was visualized with FigTree (Rambaut 2012).

Comparative genomics and primer design. Comparative analysis was performed using 145,929 genes from 21 sequenced genomes (the present study) and 24 published Clavibacter genomes. In order to identify gene conservation across $C$. michiganensis, we performed whole-genome clustering analyses based on sequence identity using CD-HIT software with an identity threshold set to $95 \%$ (Li and Godzik 2006). Primers were designed based upon conserved sequences that were present only in C. michiganensis and absent in other Clavibacter or bacterial strains. Primers were designed based on specificity, amplicon size, and compatibility in mPCR using Primer3 (http://bioinfo.ut.ee/ primer3-0.4.0/). Primer design was optimized to minimize secondary structure, and to have compatible annealing temperature and minimal cross dimerization. Primer specificity was tested in silico by a similarity search against the NCBI sequence database (https://blast.ncbi.nlm.nih.gov/Blast.cgi). Three primer sets, two $C$. michiganensis specific and one internal control, were designed to amplify RhuM (CMM_2694), TomA (CMM_0090), and 16S (CMM_RNA_0001) (Supplementary Table S2).

mPCR assay and limit of detection. MPCR was performed with RhuM-F/R, TomA-F1/R1, and $16 \mathrm{sR}-\mathrm{F} / \mathrm{R}$ primer pairs. The specificity of the mPCR assay was determined by using 75 C. michiganensis, 11 C. sepedonicus, 1 C. insidious, 2 C. tessellarius, 6 endophytic Clavibacter strains, and 15 other bacterial pathogens of tomato (Supplementary Table S1). Total genomic DNA was isolated with the Promega Wizard Genomic DNA Purification Kit. Each primer combination was tested using the C1000 Touch Thermal Cycler (Bio-Rad, Hercules, CA, U.S.A.). mPCR was performed in $25 \mu \mathrm{l}$ of final volume with 1 to $4 \mu \mathrm{l}$ of DNA; $0.7 \mu \mathrm{M}$ (RhuM-F/R), $0.5 \mu \mathrm{M}$ (TomA-F1/R1), and $0.3 \mu \mathrm{M}$ (16sR-F/R) primers; $4 \mu \mathrm{l}$ of GC buffer, and iProof polymerase (Bio-Rad) at $0.02 \mathrm{U} / \mu \mathrm{l}$. A temperature gradient of 58 to $65^{\circ} \mathrm{C}$ was used to determine the optimum annealing temperature. All PCR amplifications were carried out in a C1000 Touch Thermal Cycler (Bio-Rad). Final PCR conditions were as follows: initial denaturation of $98^{\circ} \mathrm{C}$ for $2 \mathrm{~min}$; followed by 30 cycles at $98^{\circ} \mathrm{C}$ for $30 \mathrm{~s}, 60^{\circ} \mathrm{C}$ for $30 \mathrm{~s}$, and $68^{\circ} \mathrm{C}$ for $1 \mathrm{~min}$; and a final extension step of $68^{\circ} \mathrm{C}$ for $7 \mathrm{~min}$. mPCR products were electrophoresed for $30 \mathrm{~min}$ at $130 \mathrm{~V}$ on a $1 \%$ agarose gels.

To evaluate the sensitivity of the MPCR assay, bacterial cultures and genomic DNA of $C$. michiganensis CASJ002 were serially diluted and used as a template. For DNA, $10 \mathrm{ng}$ of total C. michiganensis genomic DNA was diluted and used for mPCR assay in a C1000 Touch Thermal Cycler (Bio-Rad) following conditions as described above. For bacterial cultures, $C$. michiganensis (CASJ002) was grown on TBY broth and cells were serially diluted followed by DNA extraction using the lysis method. Each of the dilutions $(100 \mu \mathrm{l})$ was spread on TBY and incubated for $48 \mathrm{~h}$ at $28^{\circ} \mathrm{C}$ to determine the concentration of cells in the suspension.

Plant growth and pathogenicity assays. Tomato cultivar Early Pak 7 (EP-7) was grown in the greenhouse at $23^{\circ} \mathrm{C}$ and $50 \%$ relative humidity with a 14 -h photoperiod and supplemental lighting as necessary (Thapa et al. 2015). Tomato plants ( 3 to 4 weeks old) were used for inoculation assays. Tomato plants were inoculated 
with $C$. michiganensis strain CASJ002 as previously described (Thapa et al. 2017). To obtain DNA from inoculated plants, samples were collected 7 and 14 days postinoculation. Stem segments $(1 \mathrm{~cm}$ each) were cut at 1, 3, 6, 9, and $15 \mathrm{~cm}$ above the inoculation site and from apical regions. Stem segments were surface disinfected in $75 \%$ ethanol, the outer epidermis was removed, and the remaining segment was ground in $500 \mu \mathrm{l}$ of $\mathrm{dH}_{2} \mathrm{O}$. Then, $100 \mu \mathrm{l}$ of the resulting supernatant was used for DNA extraction using CTAB, and $100 \mu \mathrm{l}$ was used for determination of bacterial titers.

Seed infestation, sampling, and DNA extraction. For seed contamination, CASJ002 inoculum was prepared as described above. Inoculum was prepared by diluting cells in $10 \mathrm{mM} \mathrm{MgCl}_{2}$ to a concentration of approximately $10^{7} \mathrm{CFU} / \mathrm{ml}$. EP-7 seed lots $(10 \mathrm{~g})$ were then incubated with $40 \mathrm{ml}$ of $C$. michiganensis CASJ002 in $\mathrm{H}_{2} \mathrm{O}$ for $24 \mathrm{~h}$ at $37^{\circ} \mathrm{C}$. After $24 \mathrm{~h}$, the liquid was removed and seed were dried at $24^{\circ} \mathrm{C}$ on filter paper for 2 days and kept for 2 to 5 weeks at room temperature. The detection threshold was evaluated by adding different numbers of contaminated seed to clean seed samples of 10,000 seeds. Samples of 10,000 seeds (approximately $30 \mathrm{~g}$ ) were suspended in $120 \mathrm{ml}$ of sterile phosphate-buffered saline buffer. The samples were incubated at $4^{\circ} \mathrm{C}$ for at least $12 \mathrm{~h}$, shaken for 2 to $3 \mathrm{~h}$ at room temperature, then transferred to whirl pack bags (Whirl-pak Nasco, Modesto, CA, U.S.A.) and processed in a stomacher (Stomacher 400, Seward, England) for $20 \mathrm{~min}$. Both the lysis and CTAB procedure were used for the isolation of DNA to be used for mPCR. The PCR conditions used were as described above.

Collection of field samples. During 2016, 21 samples of fieldgrown tomato plants exhibiting bacterial canker-like symptoms were collected from the California Central Valley (Supplementary Table S3). Stem and leaf samples of plants exhibiting disease symptoms were used for DNA extraction and bacterial isolation. DNA was extracted from $1 \mathrm{mg}$ of plant materials using both lysis and CTAB procedures and used in mPCR tests. C. michiganensis isolation was performed using the semiselective D2 media (Kado and Heskett 1970).

Accession numbers. Whole-genome sequences of strains sequenced in this study were submitted to NCBI under the accession numbers listed in Table 1.

\section{RESULTS}

C. michiganensis genome sequencing and phylogenomics. We sequenced 21 C. michiganensis genomes from strains isolated from different locations worldwide using the Illumina platform (Supplementary Fig. S1A). These 21 C. michiganensis strains were

TABLE 1. Genome statistics and GenBank accession numbers of Clavibacter genomes analyzed in this study

\begin{tabular}{|c|c|c|c|c|c|c|}
\hline Species & Strains $^{\mathrm{a}}$ & Source & Contigs $(n)$ & Note & Genome size (bp) & Accession number \\
\hline Clavibacter michiganensis & ARZ28 & United States & 434 & This study & $3,281,597$ & QLNE00000000 \\
\hline C. michiganensis & ATCC10202 & $\ldots$ & 334 & This study & $3,275,372$ & QLMX00000000 \\
\hline C. michiganensis & ATCC14456 & Italy & 41 & This study & $3,296,963$ & QLMU00000000 \\
\hline C. michiganensis & CFBP1465 & France & 66 & This study & $3,328,034$ & QLMV00000000 \\
\hline C. michiganensis & CFBP1940 & Spain & 35 & This study & $3,296,592$ & QLMW00000000 \\
\hline C. michiganensis & CFBP2494 & Algeria & 39 & This study & $3,316,980$ & QLMY00000000 \\
\hline C. michiganensis & CFBP2500 & Algeria & 332 & This study & $3,305,560$ & QLMZ00000000 \\
\hline C. michiganensis & CFBP5842 & Brazil & 127 & This study & $3,343,022$ & QLNA00000000 \\
\hline C. michiganensis & CFBP6885 & France & 25 & This study & $3,327,889$ & QLML00000000 \\
\hline C. michiganensis & CFBP7158 & New Zealand & 23 & This study & $3,285,302$ & QLNB00000000 \\
\hline C. michiganensis & CFBP7311 & Morocco & 46 & This study & $3,301,380$ & QLNC00000000 \\
\hline C. michiganensis & CFBP7312 & China & 43 & This study & $3,319,896$ & QLND00000000 \\
\hline C. michiganensis & CFBP7314 & United States & 30 & This study & $3,268,866$ & QLMM00000000 \\
\hline C. michiganensis & CFBP7315 & United States & 31 & This study & $3,311,336$ & QLMN00000000 \\
\hline C. michiganensis & CFBP7316 & United States & 29 & This study & $3,258,979$ & QLMO00000000 \\
\hline C. michiganensis & CFBP7488 & France & 55 & This study & $3,299,275$ & QLMP00000000 \\
\hline C. michiganensis & CFBP7568 & United States & 61 & This study & $3,347,875$ & QLMQ00000000 \\
\hline C. michiganensis & CFBP7589 & Belgium & 35 & This study & $3,316,741$ & QLMR00000000 \\
\hline C. michiganensis & NZ1811 & New Zealand & 333 & This study & $3,273,907$ & QLMS00000000 \\
\hline C. michiganensis & NZ5026 & United States & 263 & This study & $3,283,188$ & QLMT00000000 \\
\hline C. michiganensis & NZ2541 & United Kingdom & 292 & This study & $3,321,838$ & QODA00000000 \\
\hline C. michiganensis & CASJ001 & United States & 4 & GenBank & $3,423,339$ & MDHB00000000 \\
\hline C. michiganensis & CASJ002 & United States & 3 & GenBank & $3,423,641$ & MDHC00000000 \\
\hline C. michiganensis & CASJ003 & United States & 315 & GenBank & $3,294,503$ & MDHD00000000 \\
\hline C. michiganensis & CASJ004 & United States & 477 & GenBank & $3,351,833$ & MDHE00000000 \\
\hline C. michiganensis & CASJ005 & United States & 321 & GenBank & $3,284,480$ & MDHF00000000 \\
\hline C. michiganensis & CASJ006 & United States & 4 & GenBank & $3,499,162$ & MDHG00000000 \\
\hline C. michiganensis & CASJ007 & United States & 11 & GenBank & $3,400,049$ & MDHH00000000 \\
\hline C. michiganensis & CASJ008 & United States & 39 & GenBank & $3,392,817$ & MDHI00000000 \\
\hline C. michiganensis & LMG7333 & Hungary & 5 & GenBank & $3,391,512$ & NZ_MZMP00000000.1 \\
\hline C. michiganensis & VKMAc & Hungary & 13 & GenBank & $3,295,160$ & NZ_FVZG00000000.1 \\
\hline C. michiganensis & CAYO001 & United States & 3 & GenBank & $3,481,307$ & MDHL00000000 \\
\hline C. michiganensis & CA00001 & United States & 120 & GenBank & $3,625,805$ & MDHK00000000 \\
\hline C. michiganensis & CA00002 & United States & 4 & GenBank & $3,371,744$ & MDHM00000000 \\
\hline C. michiganensis & NCPPB382 & United Kingdom & $\ldots$ & GenBank & $3,395,240$ & AM711867.1 \\
\hline C. sepedonicus & ATCC33113 & $\ldots$ & 1 & GenBank & $3,258,645$ & NC_010407.1 \\
\hline C. insidiosus & LMG3663 & United States & 3 & GenBank & $3,387,165$ & NZ_MZMO00000000.1 \\
\hline C. capcisi & PF008 & South Korea & 3 & GenBank & $3,056,296$ & NZ_CP012573 \\
\hline C. tessellarius & ATCC33566 & United States & 2 & GenBank & $3,318,535$ & MZ̄MQ00000000.1 \\
\hline C. nebraskensis & NCPPB2581 & United States & 1 & GenBank & $3,063,596$ & NC_020891.1 \\
\hline Clavibacter spp. & CFBP7494 & Chile & 15 & GenBank & $3,425,817$ & MDJW00000000 \\
\hline Clavibacter spp. & CFBP7576 & $\ldots$ & 372 & GenBank & $3,399,000$ & MDJX00000000 \\
\hline Clavibacter spp. & CFBP8017 & The Netherlands & 65 & GenBank & $3,284,576$ & MDJY00000000 \\
\hline Clavibacter spp. & CFBP8019 & The Netherlands & 18 & GenBank & $3,076,288$ & MDJZ00000000 \\
\hline Clavibacter spp. & LMG26808 & The Netherlands & 70 & GenBank & $3,420,753$ & NZ_AZQZ01000000 \\
\hline
\end{tabular}

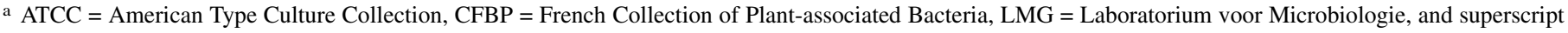
$\mathrm{T}=$ type strain. 
verified to be pathogenic on tomato after inoculation of the cultivar EP-7 and were able to induce leaflet necrosis, wilting, and stem canker symptoms (Fig. 1). Genomes were sequenced on the Illumina platform, de novo assembled with the SPAdes, and annotated with Prokka and the NCBI Prokaryotic Genome Annotation Pipeline (Table 1). To facilitate a high-resolution comparison of Clavibacter spp., the core genome of all 21 strains sequenced in the present study and 16 other published genomes, including five Clavibacter spp. pathogenic on other crops and five tomato endophytes, were analyzed. Using the orthoMCL pipeline, we identified a total of 1,258 orthologous genes that are conserved between different Clavibacter spp. (Supplementary Fig. S2). The 1,258 orthologous genes were concatenated and a maximumlikelihood approach was employed to generate a Clavibacter phylogeny (Fig. 1). C. michiganensis strains formed a monophyletic clade strongly supported by a high bootstrap value (100\%) and clearly separated from other Clavibacter spp. The phylogenetic analyses also refined the genetic relationship among the C. michiganensis strains (Fig. 1). The relatedness among C. michiganensis strains does not correlate with geographical location or year of isolation. This is likely due to the global production and distribution of tomato seed, making it extremely hard to trace geographic origins of strains or sources. Collectively, these data demonstrate that $C$. michiganensis strains are not clonal and support the concept of multiple independent introductions, consistent with seedborne disease.

All Clavibacter genomes contained one circular chromosome approximately $3.2 \mathrm{Mb}$ in size, encoding an average of approximately 3,200 protein-coding sequences per genome (Table 1; Supplementary Fig. S1B and C). Plasmids with similarity to pCM1 and pCM2, which are found in reference strain NCPPB382, were detected based on similarity in their plasmid backbone (replication or partitioning genes) and conjugal transfer genes. C. michiganensis strains possessed at least one virulence plasmid of the pCM1 or pCM2 type (Fig. 1) (Meletzus et al. 1993). Of the 34 C. michiganensis genomes analyzed, 33 possessed pCM1-like plasmids, while 29 possessed pCM2-like plasmids (Fig. 1). Both plasmids are required for virulence in NCPPB382 (Meletzus et al. 1993). However, we have identified multiple $C$. michiganensis strains with only pCM2 that retain pathogenicity (Thapa et al. 2017) (Fig. 1). In addition, the C. michiganensis strain NZ2541 lacks pCM1 but is still pathogenic on tomato (Figs. 1 and 2). We compared the genomes of reference C. michiganensis strain NCPPB382 with strains NZ2541, which lacks pCM1, and CASJ001, which lacks pCM2. Genome visualizations were performed using circos (Supplementary Fig. S1B and C) (Krzywinski et al. 2009). Although the plasmid components of C. michiganensis strains NCPPB382, NZ2541, and CASJ001 differ, they display a high level of chromosomal sequence similarity

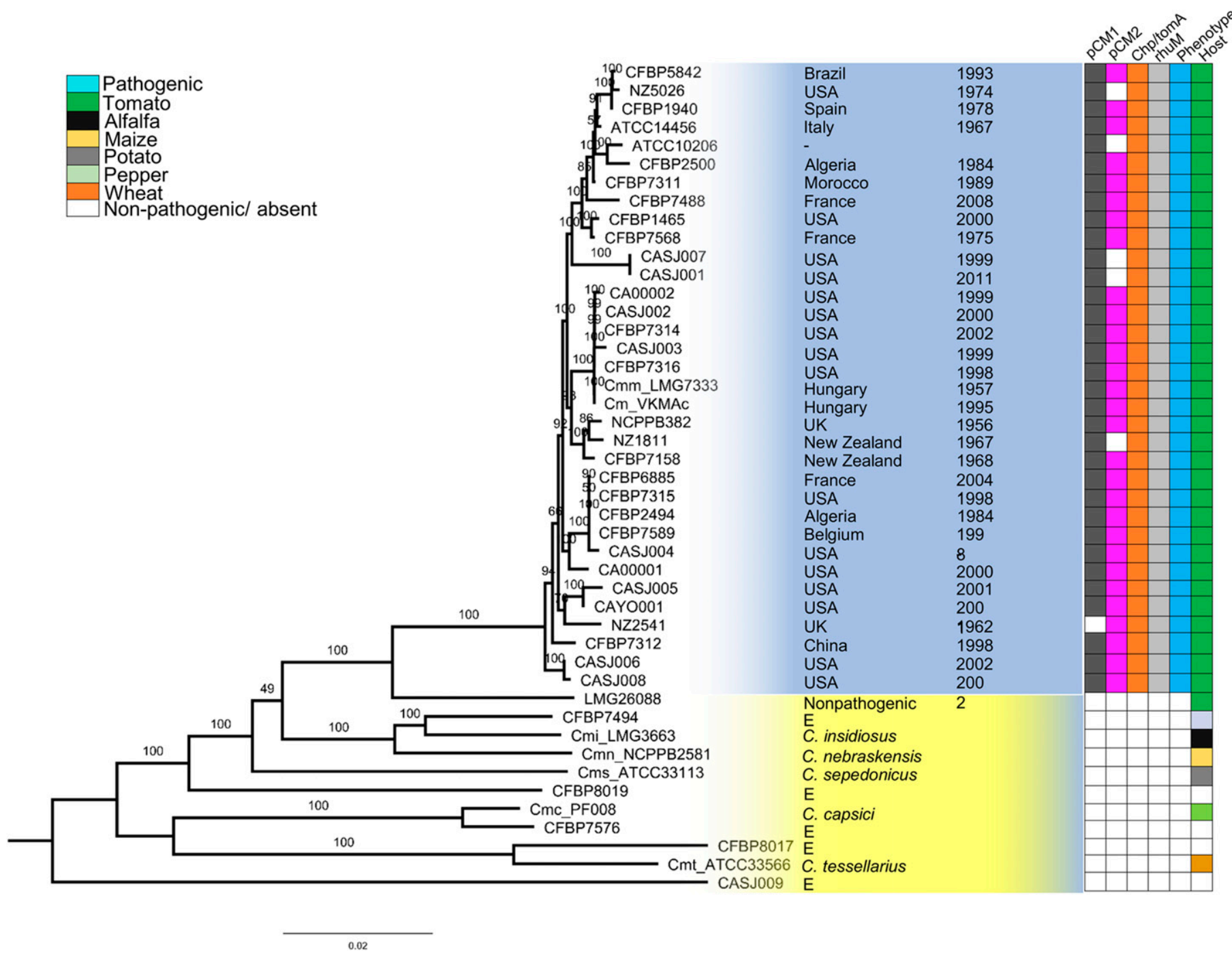

Fig. 1. Genome-assisted phylogeny of the genus Clavibacter. In total, 1,258 orthologous genes from each strain were concatenated. A maximum-likelihood approach was used to generate the phylogeny with 1,000 bootstrap replicates. Bootstrap values are indicated at each node. Columns indicate the presence of the pCM1 plasmid, the pCM2 plasmid, the chp/tomA genomic island, and rhuM. Phenotype $=$ shading indicates pathogenicity on tomato, Host $=$ plants bacteria were isolated from if known, and $\mathrm{E}=$ endophyte of tomato. 
(Supplementary Fig. S1B and C). We also detected some instances of genome rearrangement between $C$. michiganensis strains, including CASJ001 and NZ2541 (Supplementary Fig. S1B and C).

Although there is significant variation within pCM1-like plasmids, the celA gene is conserved in the pCM1 plasmids of all C. michiganensis strains analyzed (Fig. 1). Previously, it was demonstrated that celA is required for the induction of bacterial wilt of tomato in NCPPB382 and CASJ002 (Jahr et al. 2000; Thapa et al. 2017). However, NZ2541 also causes canker symptoms on tomato and grows to levels similar to those of NCPPB382 and CASJ002, even though it lacks pCM1 and celA (Fig. 2). Strain NZ2541 contains pCM2 in addition to a novel plasmid that we have named pCM3 (Fig. 2A). These data highlight the genetic variation present in $C$. michiganensis plasmid types.

Comparative genomics and design of $C$. michiganensisspecific primers. Our genomic analyses of diverse Clavibacter strains indicated that several of the existing $C$. michiganensisspecific primers were likely nonspecific, considering the differences in plasmid content and composition (Supplementary Table S2). We analyzed eight primer pairs for specificity in detecting C. michiganensis: $\mathrm{PFC} 3 / 5, \mathrm{P} 5 / 6$, ppA, tomA, celA, Cmm3/4, Cmm5/6, and PSA (Dreier et al. 1995; Jahr et al. 2000; Kleitman et al. 2008; Pastrik and Rainey 1999; Santos et al. 1997). In order to determine the specificity of commonly used published primers, we tested them on a panel of 110 bacterial strains, including 75 C. michiganensis strains, 20 other Clavibacter strains, 6 Pseudomonas spp., and 9 Xanthomonas spp. (Supplementary Table
$\mathrm{S} 1$ and S2). Of the eight tested primer pairs, only the tomA-F/R pair, amplifying the tomA tomatinase on the $\operatorname{chp} /$ tom $A$ genomic island, specifically detected all pathogenic $C$. michiganensis strains but not other Clavibacter spp. or subspecies (Supplementary Table S2).

Given the genetic diversity of $C$. michiganensis and variation in plasmid types, we sought to identify multiple genetic loci conserved among and specific to $C$. michiganensis. To identify C. michiganensis-specific loci, we performed whole-genome comparisons of 145,929 genes from 45 Clavibacter genomes. We identified $C$. michiganensis-specific loci and tested 10 primer pairs whose amplicons could be separated by size by gel electrophoreses after amplification in a single mPCR assay. From these primer pairs, two targets were chosen: rhuM (hypothetical protein) (CMM_2694) and tomA (tomatinase) (CMM_0090) due to their high amplification efficiency (Figs. 1 and 3A). The sequences of these genes were compared individually to the $\mathrm{nr}$ and the microbial genome databases of the NCBI BLAST web site to confirm their specificity. These results revealed that tomA and $r h u M$ are highly conserved among C. michiganensis and similar nucleotide sequences are not found in other bacteria (Fig. 3). The amplification specificity of the tomA and rhuM primer pairs was confirmed in PCR tests with DNA of a bacterial panel by PCR (Supplementary Table S1).

The mPCR assay targeted three loci, two of which are C. michiganensis specific (tomA and rhuM) and a third amplifying a region of the $16 \mathrm{~S}$ ribosomal RNA (rRNA) in bacteria and plant mitochondria that serves as an internal positive control. Primer sets were designed to possess similar melting temperatures (58 to

A

NCPPB382 pCM1

NZ2541 pCM

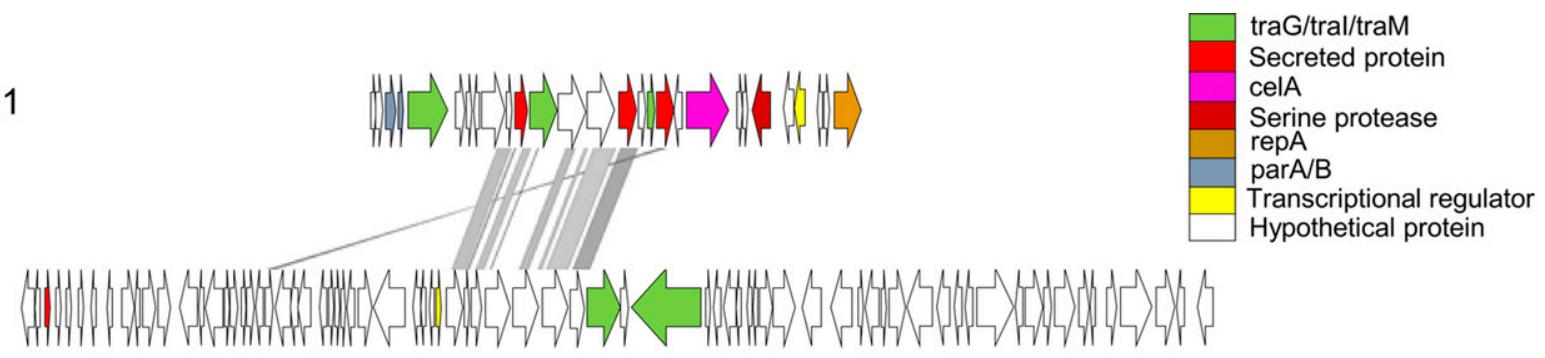

B
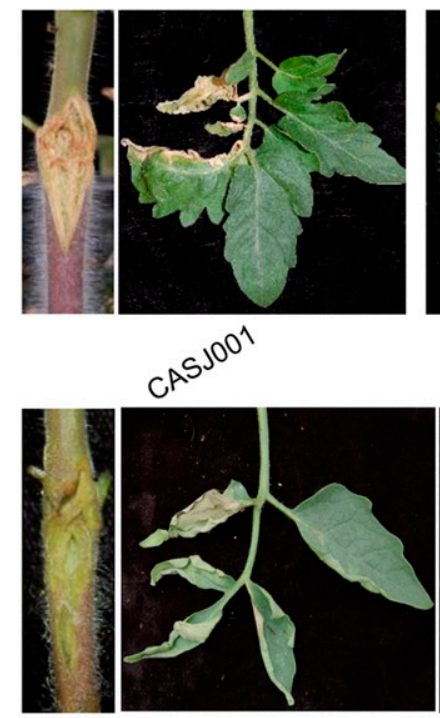

$\sqrt{2254^{4}}$
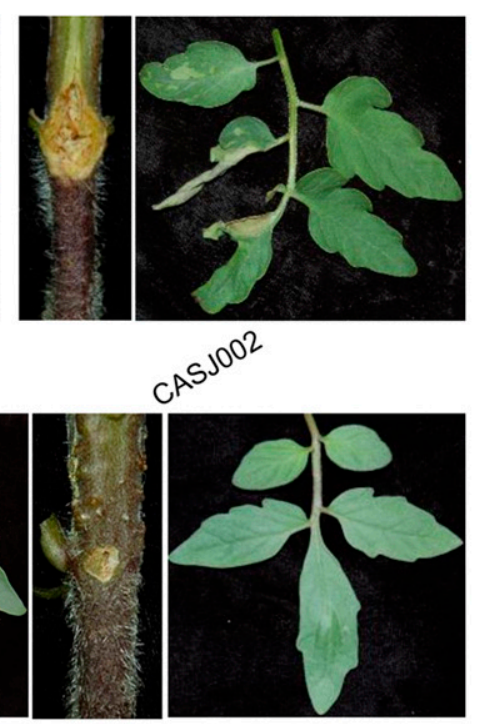

$C^{4} \mathrm{~A}^{100^{09}}$
C

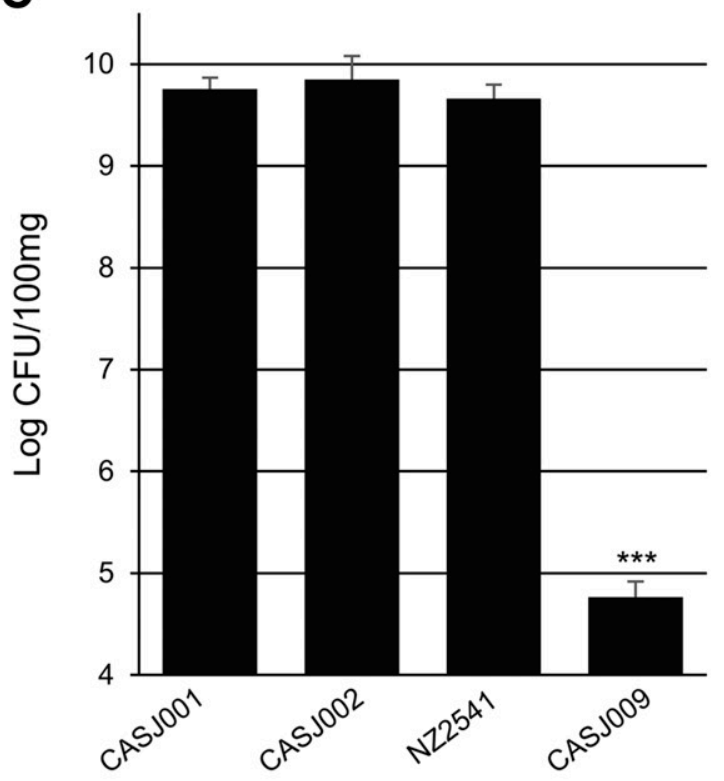

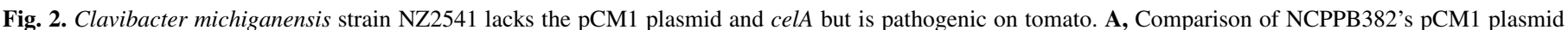

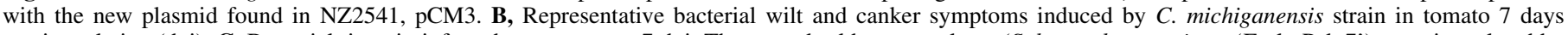

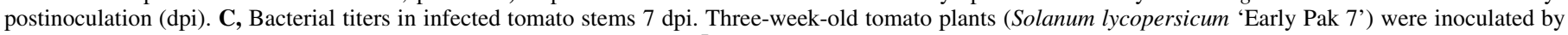

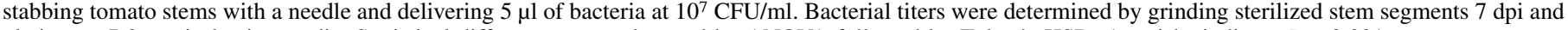
plating on D2 semiselective media. Statistical differences were detected by ANOVA followed by Tukey's HSD. Asterisks indicate $P=0.001$. 
$63^{\circ} \mathrm{C}$ ), direct the amplification of the conserved C. michiganensis sequences, and produce PCR product sizes so that the amplicons could be readily distinguished. The primer sets directed the amplification of a 1,000-bp rhuM fragment, a 630-bp tomA fragment, and a 415-bp 16S rRNA fragment (Fig. 3B).

Validation of the $C$. michiganensis MPCR assay. The specificity of the mPCR assay was determined by analyzing 75 C. michiganensis strains, 20 other Clavibacter strains, and 15 nonClavibacter spp. (Supplementary Table S1). The RhuMF/R and TomA-F1/R1 primer sets directed the amplification of the target sequences from C. michiganensis strains but not from DNA of other Clavibacter spp. or other bacteria (Fig. 3B). The mPCR amplified the three expected size fragments of $1,000 \mathrm{bp}$ (rhuM), $630 \mathrm{bp}$ (tomA), and 415 bp (16S rRNA) when purified $C$. michiganensis DNA was used as a template (Fig. 3B). No false positives were detected with Clavibacter endophytes, Clavibacter pathogens on other crops, or other bacterial pathogens of tomato, demonstrating the specificity of the mPCR assay (Figs. 3B and 4B). In contrast, the 415-bp 16S rRNA fragment was amplified from tomato and all bacterial strains tested, validating the utility of the internal positive control. The identity of selected PCR products was confirmed by sequencing.

We next evaluated the limit of detection of the MPCR assay. The detection limit was $0.01 \mathrm{ng}$ with CTAB-purified genomic DNA from $C$. michiganensis strain CASJ002 grown in pure culture (Supplementary Fig. S3A). We also analyzed the ability to detect C. michiganensis after serially diluting cultures of C. michiganensis strain CASJ002 followed by simple DNA extraction using the lysis method and were able to reliably detect 500 cells (Supplementary Fig. S3B). Similar detection levels were found for C. michiganensis strain NCPPB382 with both extraction methods (data not shown).

mPCR can detect $C$. michiganensis in contaminated plant and seed samples. To determine the capacity of the mPCR assay for detection of $C$. michiganensis in planta, we extracted DNA with the CTAB method from inoculated tomato plants (cultivar EP-7) under greenhouse conditions. Samples were collected at 7

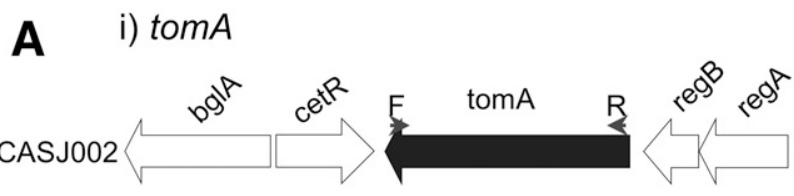

ii) rhuM

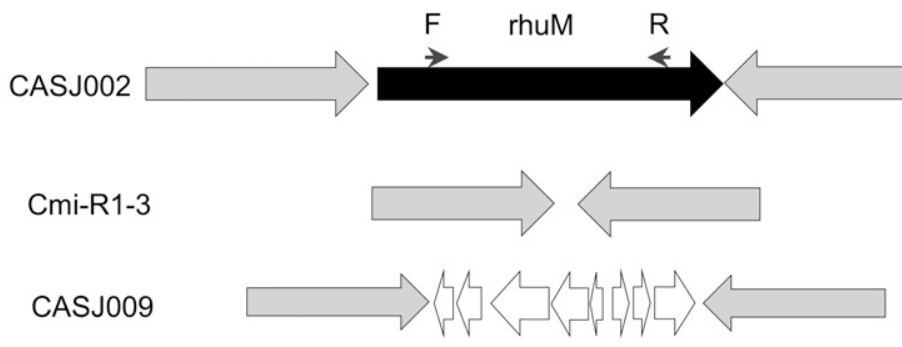

B

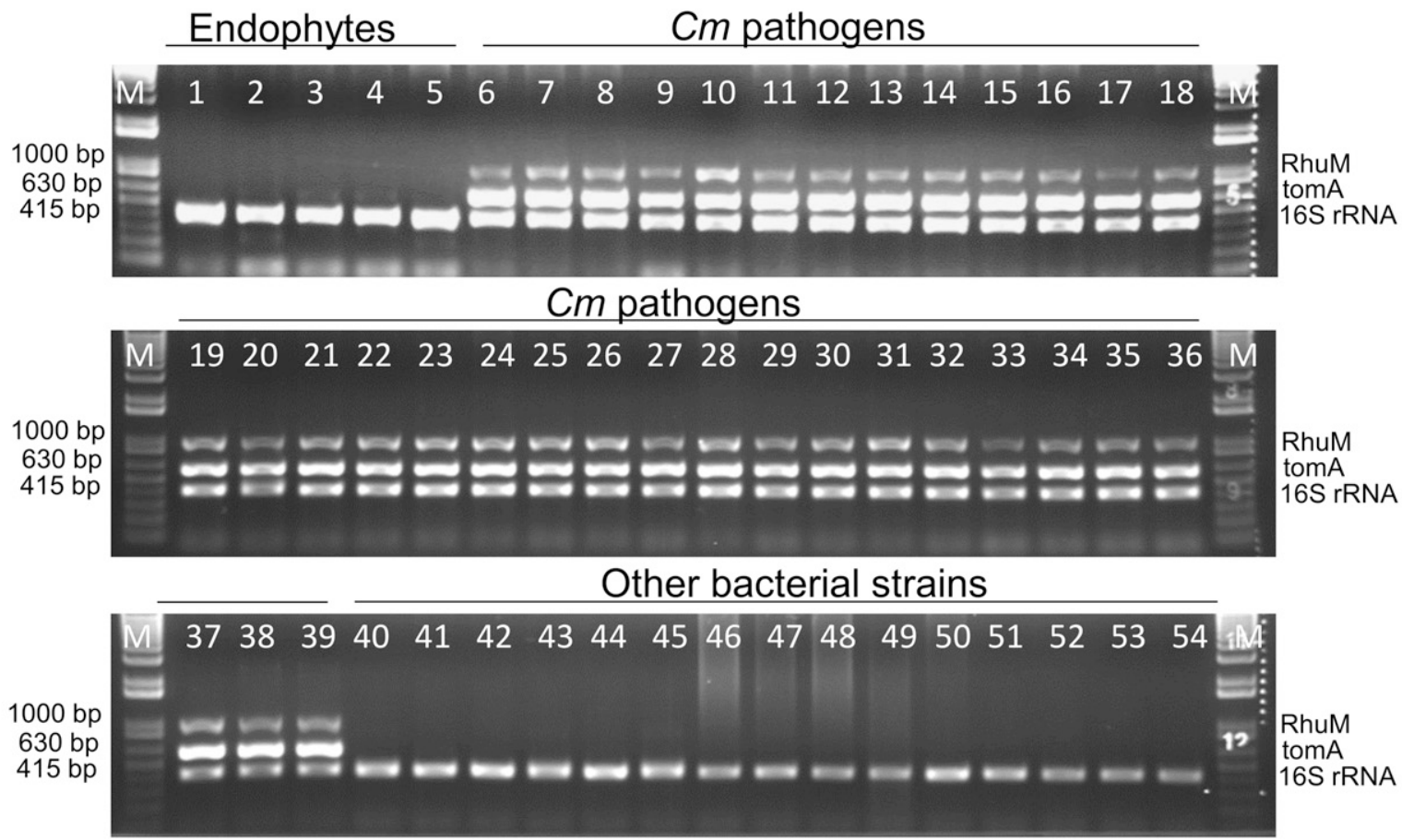

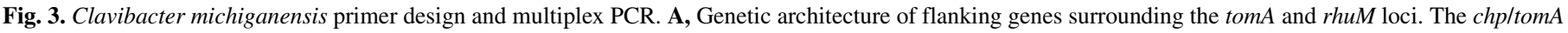

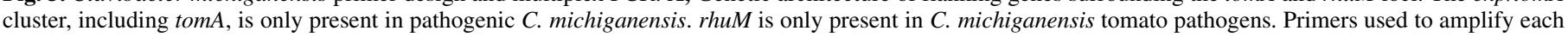

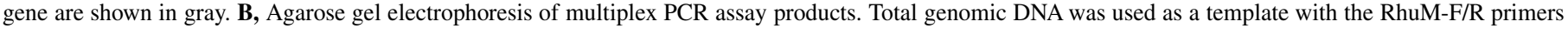

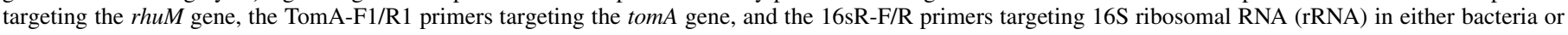

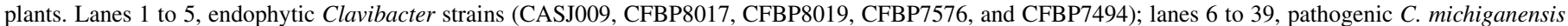

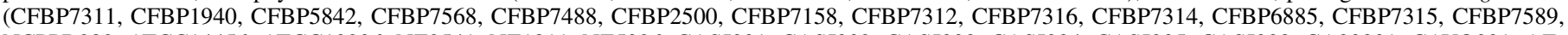

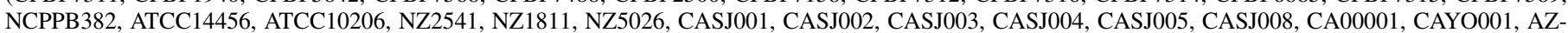

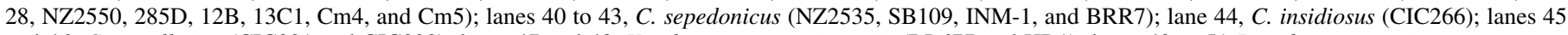

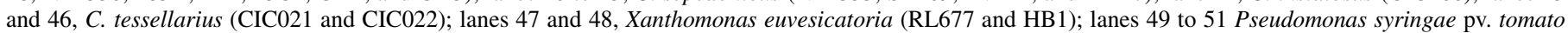

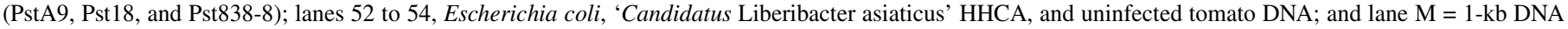
ladder. 
and 14 days postinoculation from 1, 2, 3, 6, 9, and $15 \mathrm{~cm}$ above the inoculation site, including from leaves. Samples were ground and split in two for DNA extraction and determining bacterial titers (Fig. 4). C. michiganensis was detected from all stem and leaf tissue samples of inoculated plants at both time points, whereas it was not detected from mock-inoculated controls (Fig. 4). Under our experimental conditions, wilting disease symptoms were visible at 5 to 7 days postinoculation. For infected samples, the expected

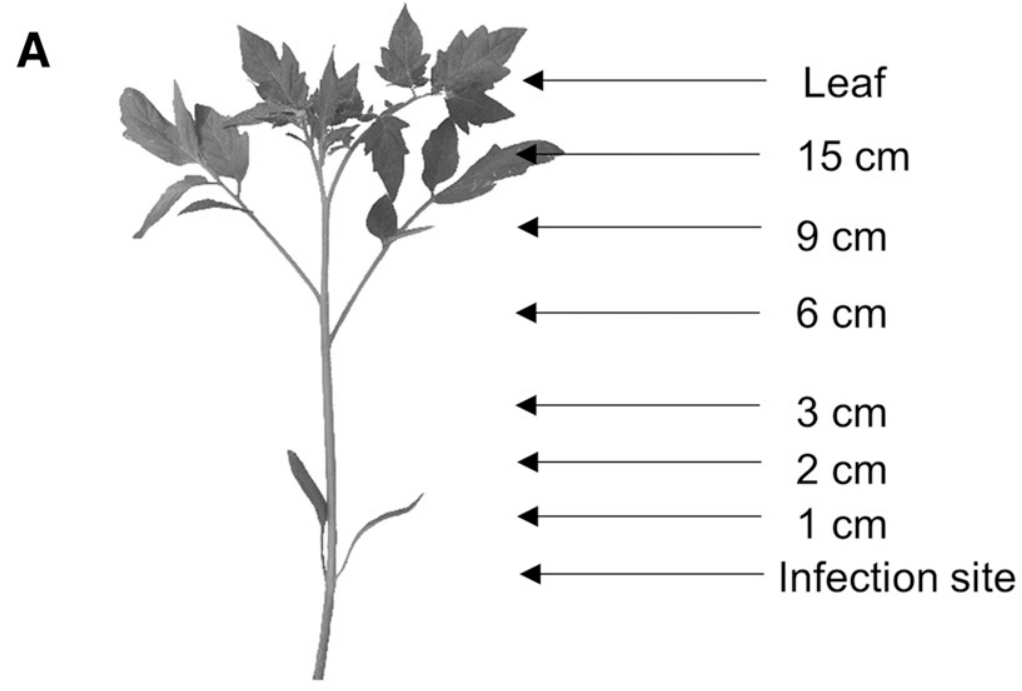

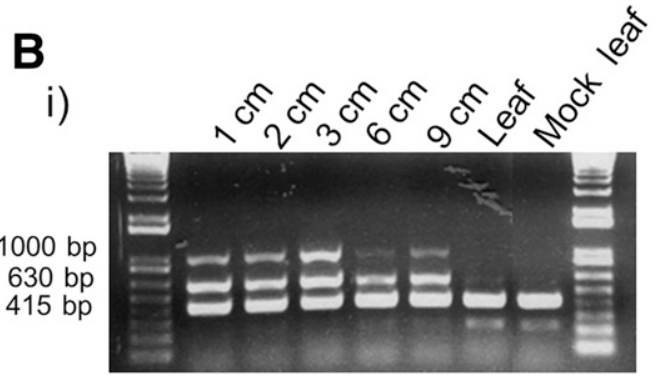

ii)
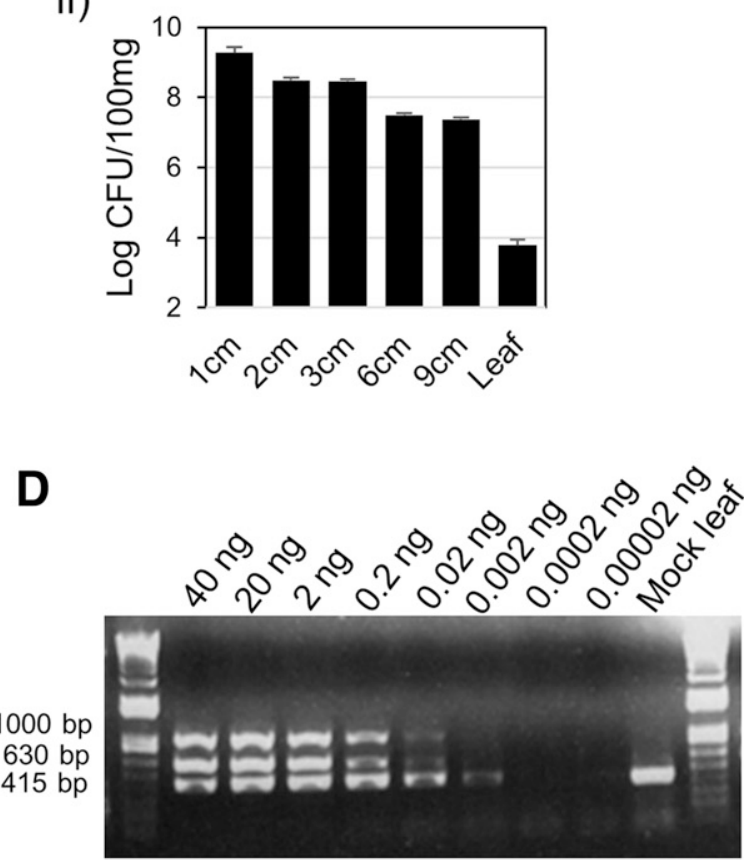

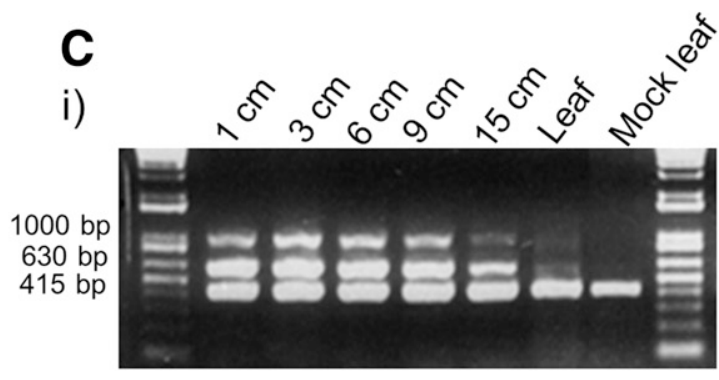

ii)

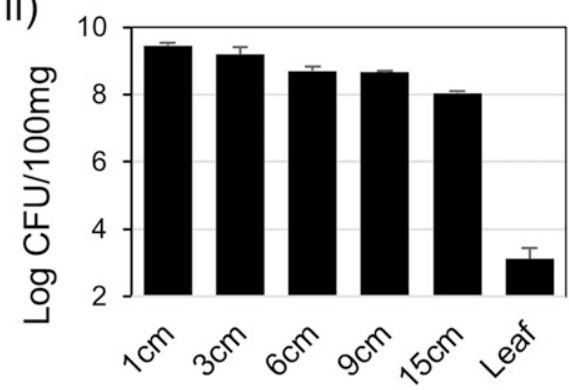

E
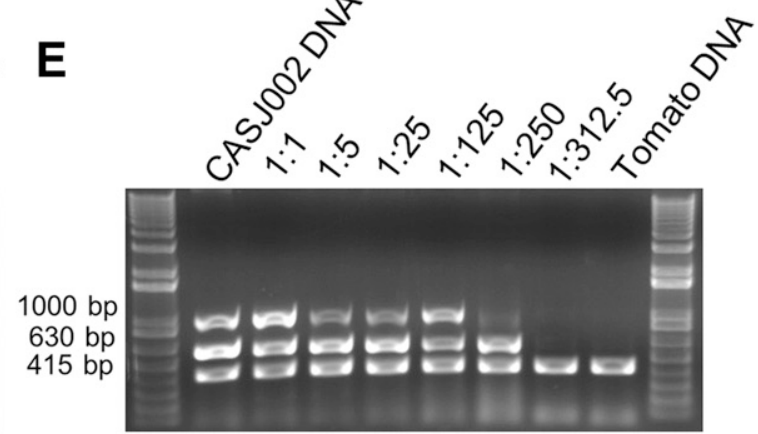

Fig. 4. Detection of Clavibacter michiganensis in infected plant materials. A, Three-week-old tomato plants (Solanum lycopersicum 'Early Pak 7') were stabbed with a needle and inoculated with $5 \mu \mathrm{l}$ of a suspension of CASJ002 at $10^{7} \mathrm{CFU} / \mathrm{ml}$. The diagram indicates points of sample collection above the $C$. michiganensis inoculation site. B, i and ii, Detection of $C$. michiganensis by multiplex PCR and bacterial titers in inoculated tomato plants 7 days postinoculation (dpi). DNA was extracted from $100 \mathrm{mg}$ of plant tissue with the cetyltrimethylammonium bromide (CTAB) method, resuspended in $50 \mu 1$ of water, and $2 \mu 1$ of DNA was used per multiplex PCR. C, i and ii, Detection of $C$. michiganensis by multiplex PCR and bacterial titers in CASJ002-inoculated tomato plants at 14 dpi. Bacterial titers, DNA extraction, and multiplex PCR were performed as described in B. D, Detection limit for CASJ002 after CTAB DNA extraction from tomato stems. DNA was extracted from plant samples $9 \mathrm{~cm}$ above the site of inoculation at 7 dpi. DNA samples were diluted and the total DNA concentration in each multiplex PCR is indicated above each lane. E, Detection of $C$. michiganensis by multiplex PCR in serial dilutions of CASJ002 DNA (50 ng) and healthy tomato plant DNA (50 ng) mixed in different ratios using $100 \mathrm{ng} / \mu \mathrm{l}$ in a $25-\mu \mathrm{l}$ PCR. Numbers indicate bacterial/plant DNA ratios. Lane $\mathrm{M}=$ size marker (1-kb DNA ladder). 
amplicons of 1,000 bp (rhuM), $630 \mathrm{bp}$ (tomA), and $415 \mathrm{bp}$ (16S rRNA) were observed, whereas only the 415-bp fragment was observed for DNA extracted from mock-inoculated plants (Fig. 4Bi and $\mathrm{Ci}$ ). We did not collect samples at $15 \mathrm{~cm}$ above the inoculation site at 7 days postinoculation because the plants were too small in height at this time point. However, the MPCR assay was able to detect $C$. michiganensis up to $9 \mathrm{~cm}$ above the inoculation site at 7 days postinoculation (Fig. 4Bi). The mPCR assay was able to detect $C$. michiganensis up to $15 \mathrm{~cm}$ above the site of infection at 14 days postinoculation, which corresponded to $8 \mathrm{log} \mathrm{CFU} / \mathrm{mg}$ of plant tissue (Fig. 4C ii).

The limit of detection of the mPCR assay in plant samples was also determined. DNA was isolated from tomato plants with the CTAB method (cultivar EP-7). The bacterial titers were experimentally determined as previously described and used to calculate the limit of detection (Fig. 4D). The level of sensitivity for in planta detection was similar to that obtained with the bacterial cultures, and we were able to detect $C$. michiganensis in $0.02 \mathrm{ng}$ of plant DNA, corresponding to approximately $10^{3} \mathrm{C}$. michiganensis cells per PCR (Fig. 4D). The sensitivity of the mPCR was also evaluated by spiking $C$. michiganensis CASJ002 DNA into uninfected tomato DNA samples in bacterial/tomato DNA ratios 1:1, 1:5, 1:25, 1:125, $1: 250$, and $1: 312.5$ with dilution of $100 \mathrm{ng} / \mu \mathrm{l}$ in each PCR. In these experiments, $C$. michiganensis was detected down to a C. michiganensis/tomato DNA dilution of 1:250 (Fig. 4E).

We also tested the mPCR assay for detection of $C$. michiganensis in DNA extracted from artificially infested seed. Different concentrations of $C$. michiganensis strain CASJ002 were used to infest tomato seed, followed by DNA extraction and mPCR (Fig. 5A). The mPCR assay was able to detect $C$. michiganensis with bacterial contamination in DNA isolated from a sample of 10 infested seeds (Fig. 5A). Next, we evaluated the mPCR for detecting C. michiganensis contamination after spiking contaminated seed into clean seed lots. Seed infested with $5 \times 10^{7}$ C. michiganensis CASJ002 were mixed with 10,0000 clean seeds in different ratios followed by DNA extraction and mPCR. The mPCR was able to detect $0.3 \%$ incidence of $C$. michiganensis contamination in seed (Fig. 5B).

Evaluation of mPCR detection from recent $C$. michiganensis field strains. In 2016, there were bacterial canker occurrences in in the California Central Valley (Supplementary Table S3). Tomato samples exhibiting symptoms of wilt, canker, and bird's eye spots on fruit were collected from fields and assayed for the presence of $C$. michiganensis (Supplementary Table S3; Supplementary Fig. S4). The three fragments—rhuM (1,000 bp), tomA (630 bp), and 16S rRNA (415 bp)-were amplified from samples with canker symptoms, whereas only the fragment corresponding to $16 \mathrm{~S}$ rRNA was amplified from healthy plants (Fig. 6A). With the mPCR assay, C. michiganensis was detected in all 21 samples with canker symptoms tested, consistent with validation of C. michiganensis from the samples on D2 medium. Furthermore, we verified the pathogenicity of selected $C$. michiganensis-like colonies by inoculating tomato EP-7. Samples that tested positive using the mPCR assay generated $C$. michiganensis-like colonies on D2 media. These colonies also caused bacterial canker disease symptoms and grew to levels similar to those of previously characterized strains, including CASJ002 (Fig. 6B and C). Taken together, these data demonstrate the specificity and utility of mPCR detection of $C$. michiganensis in field samples and diagnosis of bacterial canker.

\section{DISCUSSION}

In this study, we used a comparative genomics approach to analyze strains and species of the genus Clavibacter and used this information to develop a specific detection assay for C. michiganensis, the causal agent of bacterial canker of tomato. Here, we have identified orthologous loci that are distributed among
Clavibacter spp. In total, 1,258 core orthologous loci were used to generate high-resolution Clavibacter phylogeny, which clearly demonstrates that $C$. michiganensis is separate from other Clavibacter spp. The highly similar orthologous loci among the C. michiganensis strains also indicates their conserved function. The analyses of the $C$. michiganensis genomes supports the monophyletic nature of this pathogen. However, $C$. michiganensis strains exhibit genetic diversity when compared with each other. The chp/tomA pathogenicity island is conserved among all the C. michiganensis strains and has been previously demonstrated to be a critical virulence factor in $C$. michiganensis strain NCPPB382 (Gartemann et al. 2008; Kaup et al. 2005). Significant differences in plasmid content and composition were observed, consistent with previous findings of plasmid diversity in C. michiganensis strains from California and New York (Thapa et al. 2017). Our previous study on California $C$. michiganensis strains also had similar findings (Thapa et al. 2017). Differences in genomic island, secreted protein, and CAZymes were also observed (Tancos et al. 2015; Thapa et al. 2017).

The $C$. michiganensis strains in our present phylogeny do not cluster based on geographical origin or the year of isolation, which is consistent with seedborne disease and separate introduction events. A similar distribution pattern was observed for $C$. michiganensis outbreaks in Turkey (Baysal et al. 2011). This is also supported by studies reporting a single source of introduction by seed which persisted afterward in the region (de León et al. 2009; Jacques et al. 2012; Kawaguchi et al. 2010). Our comparative genomics approach further identified loci that are conserved in all C. michiganensis strains and absent in other Clavibacter spp. and bacterial pathogens of tomato. Of 10 loci examined, 2 were used to design a $C$. michiganensis detection assay based on mPCR. We demonstrated the power of a genomics approach for comparing a
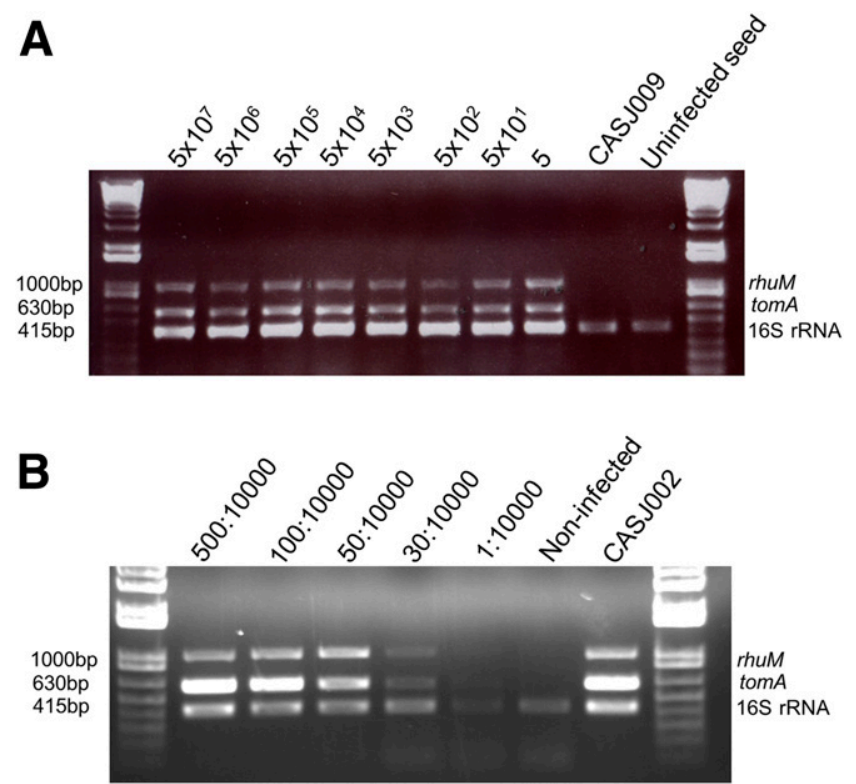

Fig. 5. Detection of Clavibacter michiganensis in seed. A, C. michiganensis multiplex PCR detection from contaminated tomato seed. Tomato seeds were contaminated with CASJOO2 at the indicated concentrations. DNA was directly extracted from 10 seeds, the pellet was resuspended in $50 \mu \mathrm{l}$, and $2 \mu \mathrm{l}$ of purified DNA was used in each multiplex PCR. B, Detection of C. michiganensis by multiplex PCR after spiking contaminated seed with clean seed lots consisting of 10,000 seeds. Seed infested with $5 \times 10^{7}$ CASJ002 were mixed with clean seed in different ratios followed by DNA extraction and multiplex PCR. Seed were incubated with $120 \mathrm{ml}$ of phosphate-buffered saline and crushed in a stomacher, and 5 to $10 \mathrm{ml}$ was used for DNA extraction. The pellet was resuspended in 100 to $200 \mu \mathrm{l}$ and 2 to $4 \mu \mathrm{l}$ of purified DNA was used in each PCR. Infested: clean seed ratios are indicated above each lane. Lane $1=1-\mathrm{kb}$ DNA ladder. 
large number of related bacterial genomes to identify specific genetic markers for pathogen detection.

The best way to manage bacterial canker disease of tomato is using a seed source free of $C$. michiganensis contaminants, extensive sanitation of equipment, removal of crop debris, and crop rotation in the field. Effective detection methods are critical for early detection of outbreaks and for detection of contaminated seed lots. Even low levels of $C$. michiganensis contamination $(0.01 \%)$ from seed to seedling can cause a disease epidemic under favorable conditions (Chang et al. 1991). Therefore, accurate detection of C. michiganensis in seed is an important component of disease management, especially given the prevalence of diverse endophytic Clavibacter strains associated with tomato. The most common detection assays for C. michiganensis are serological or PCR based, following isolation of suspect bacteria by growth on semiselective media (Alvarez et al. 2005; Dreier et al. 1995; ISHI 2017; Louws et al. 1998; Kaneshiro et al. 2006; Milijašević-Marčić et al. 2012). The serological techniques are not reliable due to their cross reaction with other Clavibacter spp. (Dreier et al. 1995; Franken et al. 1993; Jacques et al. 2012). Most of the present PCR assays for C. michiganensis are based on plasmid targets (Alvarez et al. 2005; Dreier et al. 1995; Kleitman et al. 2008; Santos et al. 1997). Whereas all pathogenic $C$. michiganensis strains possess at least one virulence plasmid, we have identified significant variation in C. michiganensis plasmid content and profiles (Thapa et al. 2017). For example, the NZ2541 strain lacks pCM1 but is able to cause disease on tomato. Furthermore, only $85 \%$ of the C. michiganensis strains sequenced possess pCM2-like plasmids. Other studies have reported $C$. michiganensis plasmid variation in field strains and plasmid loss under laboratory conditions (Kleitman et al. 2008; Tancos et al. 2015; Thapa et al. 2017). For example, the frequently used CM5/CM6 primer pair, which targets the pat-1 locus in pCM2, only directed the amplification of the target fragment from $75 \%$ of tested C. michiganensis strains, whereas the CM3/CM4 primer pair, which targets the ppaJ locus in pCM1, directed the amplification of the target fragment from $83 \%$ of tested C. michiganensis strains (Hadas et al. 2005; Louws et al. 1999; Santos et al. 1997). In the present study, these primers showed both false-positive and -negative results (Supplementary Table S2). Therefore, the published primers targeting plasmids for detection of $C$. michiganensis are not sufficiently reliable.

Diagnostic tests for pathogen presence should possess specificity, sensitivity, and reliability. In our $\mathrm{mPCR}$ diagnostic assay for C. michiganensis, we included three primer pairs that target two C. michiganensis chromosomal loci (tomA and $r h u M$ ), as well as the 16S rRNA gene as an internal control that amplifies bacterial or plant mitochondrial DNA. tomA is found in the chp/tomA pathogenicity island, which is present in all pathogenic C. michiganensis strains but is absent in Clavibacter endophytes and Clavibacter spp. infecting other crops (Kaup et al. 2005; Thapa et al. 2017). tomA encodes a putative tomatinase, which deglycosylates the antibacterial saponin $\alpha$-tomatine (Kaup et al. 2005). The rhuM gene is also conserved in all C. michiganensis strains (Supplementary Table $\mathrm{S} 1$ ). rhuM is predicted to be

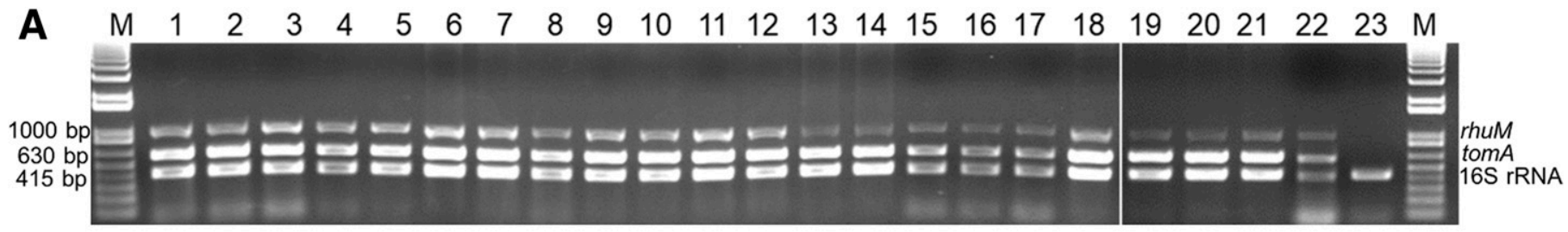

B
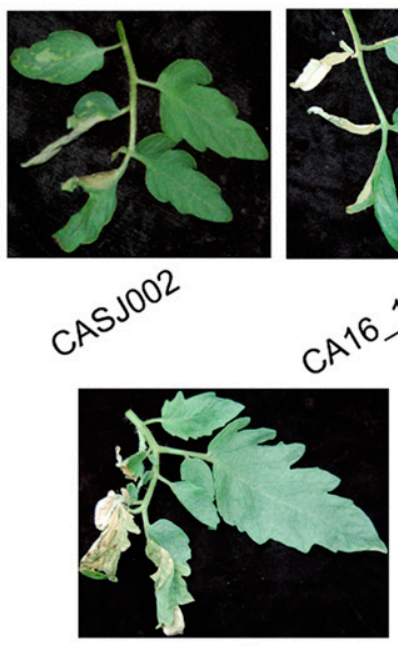

$C A^{16} r^{108^{3}}$

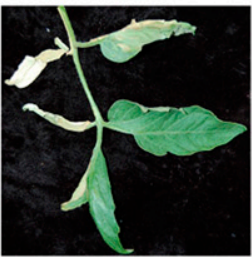

$106^{8}$
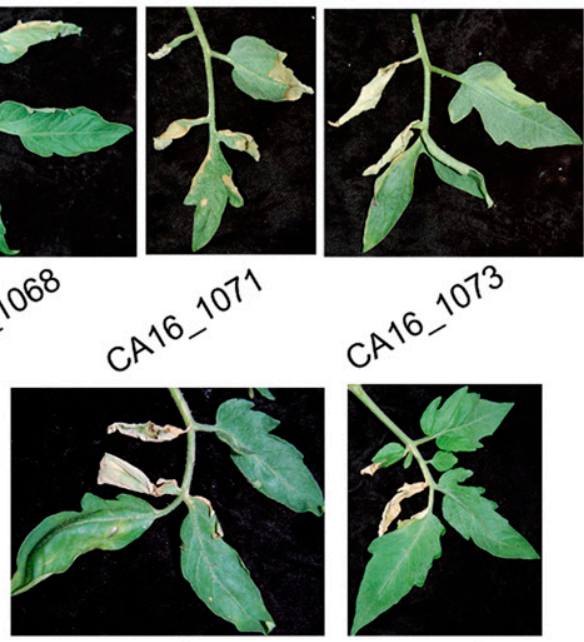

C

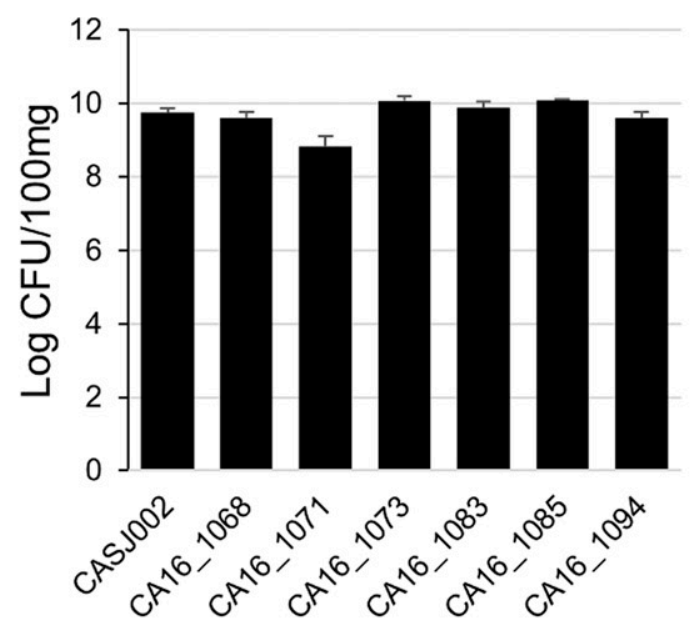

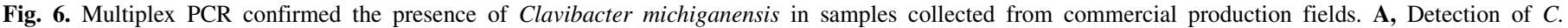

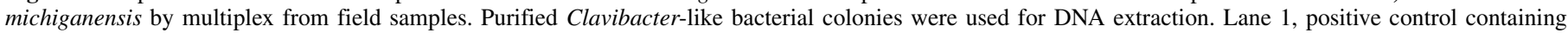

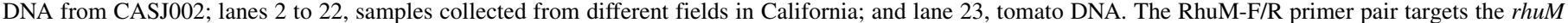

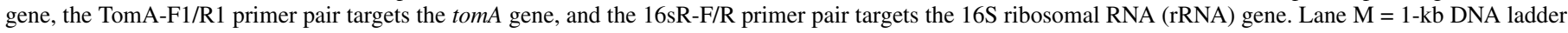

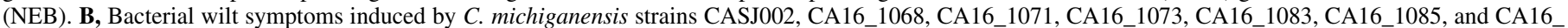

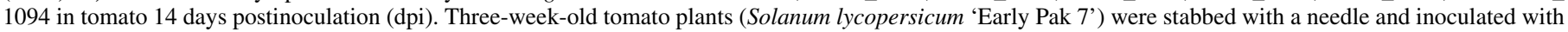

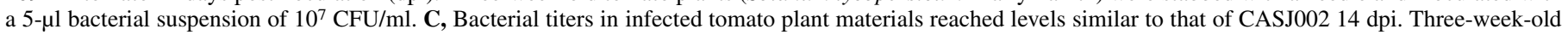

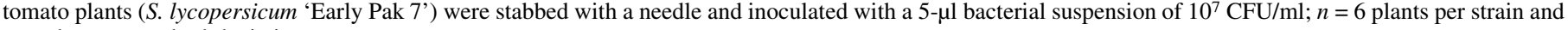
error bars $=$ standard deviation. 
involved in virulence in other bacterial pathogens based on its presence on the PAI-3 of Salmonella spp. but its function in C. michiganensis virulence remains to be determined (Bertelloni et al. 2017). We verified the specificity of the mPCR assay against 75 C. michiganensis strains, 20 other Clavibacter strains, and 15 other bacterial plant pathogens. We detected $C$. michiganensis at as little as approximately $10^{3} \mathrm{CFU} / \mathrm{ml}$, which is a level of sensitivity similar to that also reported for PCR in other studies (Dreier et al. 1995; Luo et al. 2008). We were also able to detect $C$. michiganensis from seed after artificial contamination. The $\mathrm{mPCR}$ assay reported herein proved to be a sensitive, accurate, and reliable diagnostic technique for $C$. michiganensis in infected plant materials.

Recent advancements in genome sequencing and high-throughput computing have enabled pathogen tracking and development of pathogen detection assays (Bueno-Sancho et al. 2017; Islam et al. 2016; Langlois et al. 2017; Savory et al. 2017). For instance, comparative analysis has been used to identify emergence of the Magnaporthe oryzae lineage and its origin in Bangladesh, and track and define Puccinia striiformis population structure and dispersal on a global scale (Bueno-Sancho et al. 2017; Islam et al. 2016). It has also been used for real-time monitoring of Phytophthora infestans populations for virulence and application of preventive fungicide (Li et al. 2012). Comparative genomics has also enabled specific detection and identification of different plantpathogenic bacteria (Langlois et al. 2017; Savory et al. 2017). Our results demonstrate the successful application of comparative genomics to identify specific loci for accurate detection of C. michiganensis. The genetic markers obtained from wholegenome comparative analysis used in the MPCR assay described here are specific, sensitive, and reliable for the detection of C. michiganensis in both infected tomato plants and seed. The adoption of this assay by the seed industry and diagnostic laboratories will facilitate rapid screening of infected plants and seed for routine diagnostics.

\section{ACKNOWLEDGMENTS}

We thank CIRM-CFBP (https://www6.inra.fr/cirm_eng/) for providing part of the C. michiganensis strains used in this study.

\section{LITERATURE CITED}

Alvarez, A. M., Kaneshiro, W. S., and Vine, B. G. 2005. Diversity of Clavibacter michiganensis subsp. michiganensis populations in tomato seed: What is the significance? Acta Hortic. 695:205-214.

Anonymous. 2000. European Union Council directive 2000/29/EC on protective measures against the introduction into the Community of organisms harmful to plants or plant products and against their spread within the Community. Off. J. Eur. Communities: Legis. 169:33.

Bankevich, A., Nurk, S., Antipov, D., Gurevich, A. A., Dvorkin, M., Kulikov, A. S., Lesin, V. M., Nikolenko, S. I., Pham, S., Prjibelski, A. D., Pyshkin, A. V., Sirotkin, A. V., Vyahhi, N., Tesler, G., Alekseyev, M. A., and Pevzner, P. A. 2012. SPAdes: A new genome assembly algorithm and its applications to single-cell sequencing. J. Comput. Biol. 19:455-477.

Baysal, O., Mercati, F., Ikten, H., Yildiz, R. C., Carimi, F., Aysan, Y., Jaime, A., and da Silva, T. 2011. Clavibacter michiganensis subsp. michiganensis: Tracking strains using their genetic differentiations by ISSR markers in Southern Turkey. Physiol. Mol. Plant Pathol. 75:113-119.

Bertelloni, F., Tosi, G., Massi, P., Fiorentini, L., Parigi, M., Cerri, D., and Ebani, V. V. 2017. Some pathogenic characters of paratyphoid Salmonella enterica strains isolated from poultry. Asian Pac. J. Trop. Med. 10:1161-1166.

Bertolini, E., Olmos, A., Lopez, M. M., and Cambra, M. 2003. Multiplex nested reverse transcription-polymerase chain reaction in a single tube for sensitive and simultaneous detection of four RNA viruses and Pseudomonas savastanoi pv. savastanoi in olive trees. Phytopathology 93:286-292.

Bueno-Sancho, V., Persoons, A., Hubbard, A., Cabrera-Quio, L. E., Lewis, C. M., Corredor-Moreno, P., Bunting, D. C. E., Ali, S., Chng, S., Hodson, D. P., Madariaga Burrows, R., Bryson, R., Thomas, J., Holdgate, S., and Saunders, D. G. O. 2017. Pathogenomic analysis of wheat yellow rust lineages detects seasonal variation and host specificity. Genome Biol. Evol. 9:3282-3296.
Chang, R. J., Ries, S. M., and Pataky, J. K. 1991. Dissemination of Clavibacter michiganensis subsp. michiganensis by practices used to produce tomato transplants. Phytopathology 81:1276-1281.

de León, L., Rodriguez, A., Llop, P., Lopez, M. M., and Siverio, F. 2009. Comparative study of genetic diversity of Clavibacter michiganensis subsp. michiganensis isolates from the Canary Islands by RAPD-PCR, BOX-PCR and AFLP. Plant Pathol. 58:862-871.

de León, L., Siverio, F., López, M. M., and Rodríguez, A. 2011. Clavibacter michiganensis subsp. michiganensis, a seedborne tomato pathogen: Healthy seeds are still the goal. Plant Dis. 95:1328-1338.

Dreier, J., Bermpohl, A., and Eichenlaub, R. 1995. Southern hybridization and PCR for specific detection of phytopathogenic Clavibacter michiganensis subsp. michiganensis. Phytopathology 85:462-468.

Eichenlaub, R., and Gartemann, K. H. 2011. The Clavibacter michiganensis subspecies: Molecular investigation of gram-positive bacterial plant pathogens. Annu. Rev. Phytopathol. 49:445-464.

Eichenlaub, R., Gartemann, K.-H., and Burger, A. 2006. Clavibacter michiganensis, a group of gram-positive phytopathogenic bacteria. Pages 385-421 in: Plant-Associated Bacteria. S. S. Gnanamanickam, ed. Springer Netherlands, Dordrecht, The Netherlands.

Fatmi, M., Bolkan, H., and Schaad, N. W. 2017. Detection of Clavibacter michiganensis subsp. michiganensis in tomato seed. Pages 111-117 in: Detection of Plant-Pathogenic Bacteria in Seed and other Planting Material, 2nd ed. M. Fatmi, R. R. Walcott, and N. W. Schaad, eds. The American Phytopathological Society, St. Paul, MN, U.S.A.

Fatmi, M., and Schaad, N. W. 2002. Survival of Clavibacter michiganensis ssp. michiganensis in infected tomato stems under natural field conditions in California, Ohio and Morocco. Plant Pathol. 51:149-154.

Franken, A. A. J. M., Kamminga, G. C., Snijders, W., Vanderzouwen, P. S., and Birnbaum, Y. E. 1993. Detection of Clavibacter michiganensis ssp. michiganensis in tomato seeds by immunofluorescence microscopy and dilution plating. Neth. J. Plant Pathol. 99:125-137.

Gartemann, K. H., Abt, B., Bekel, T., Burger, A., Engemann, J., Flügel, M., Gaigalat, L., Goesmann, A., Gräfen, I., Kalinowski, J., and Kaup, O. 2008. The genome sequence of the tomato-pathogenic actinomycete Clavibacter michiganensis subsp. michiganensis NCPPB382 reveals a large island involved in pathogenicity. J. Bacteriol. 190:2138-2149.

Hadas, R., Kritzman, G., Klietman, F., Gefen, T., and Manulis, S. 2005. Comparison of extraction procedures and determination of the detection threshold for Clavibacter michiganensis ssp. michiganensis in tomato seeds. Plant Pathol. 54:643-649.

ISHI. 2017. Method for the detection of Clavibacter michiganensis subsp. michiganensis on tomato seed (version 4.3.1). International Seed Health Initiative. https://www.worldseed.org/wp-content/uploads/2017/07/Tomato_ Cmm_July2017.pdf

Islam, M. T., Croll, D., Gladieux, P., Soanes, D. M., Persoons, A., Bhattacharjee, P., Hossain, M. S., Gupta, D. R., Rahman, M. M., Mahboob, M. G., Cook, N., Salam, M. U., Surovy, M. Z., Sancho, V. B., Maciel, J. L. N., NhaniJúnior, A., Castroagudín, V. L., Reges, J. T., Ceresini, P. C., Ravel, S., Kellner, R., Fournier, E., Tharreau, D., Lebrun, M.-H., McDonald, B. A., Stitt, T., Swan, D., Talbot, N. J., Saunders, D. G. O., Win, J., and Kamoun, S. 2016. Emergence of wheat blast in Bangladesh was caused by a South American lineage of Magnaporthe oryzae. BMC Biol. 14:84.

Jacques, M. A., Durand, K., Orgeur, G., Balidas, S., Fricot, C., Bonneau, S., Quillévéré, A., Audusseau, C., Olivier, V., Grimault, V., and Mathis, R. 2012. Phylogenetic analysis and polyphasic characterization of Clavibacter michiganensis strains isolated from tomato seeds reveal that nonpathogenic strains are distinct from C. michiganensis subsp. michiganensis. Appl. Environ. Microbiol. 78:8388-8402.

Jahr, H., Dreier, J., Meletzus, D., Bahro, R., and Eichenlaub, R. 2000. The endo-beta-1,4-glucanase CelA of Clavibacter michiganensis subsp. michiganensis is a pathogenicity determinant required for induction of bacterial wilt of tomato. Mol. Plant-Microbe Interact. 13:703-714.

Kado, C. I., and Heskett, M. G. 1970. Selective media for isolation of Agrobacterium, Corynebacterium, Erwinia, Pseudomonas, and Xanthomonas. Phytopathology 60:969-976.

Kaneshiro, W. S., Mizumoto, C. Y., and Alvarez, A. M. 2006. Differentiation of Clavibacter michiganensis subsp. michiganensis from seed-borne saprophytes using ELISA, Biolog and 16S rDNA sequencing. E. J. Plant Pathol. 116:45-56.

Kaup, O., Grafen, I., Zellermann, E. M., Eichenlaub, R., and Gartemann, K. H. 2005. Identification of a tomatinase in the tomato-pathogenic actinomycete Clavibacter michiganensis subsp. michiganensis NCPPB382. Mol. PlantMicrobe Interact. 18:1090-1098.

Kawaguchi, A., Tanina, K., and Inoue, K. 2010. Molecular typing and spread of Clavibacter michiganensis subsp. michiganensis in greenhouses in Japan. Plant Pathol. 59:76-83.

Kirchner, O., Gartemann, K. H., Zellermann, E. M., Eichenlaub, R., and Burger, A. 2001. A highly efficient transposon mutagenesis system for the 
tomato pathogen Clavibacter michiganensis subsp. michiganensis. Mol. Plant-Microbe Interact. 14:1312-1318.

Kleitman, F., Barash, I., Burger, A., Iraki, N., Falah, Y., Sessa, G., Weinthal, D., Chalupowicz, L., Gartemann, K. H., Eichenlaub, R., and Manulis-Sasson, S. 2008. Characterization of a Clavibacter michiganensis subsp. michiganensis population in Israel. Eur. J. Plant Pathol. 121:463-475.

Krzywinski, M., Schein, J., Birol, I., Connors, J., Gascoyne, R., Horsman, D., Jones, S. J., and Marra, M. A. 2009. Circos: An information aesthetic for comparative genomics. Genome Res. 19:1639-1645.

Kück, P., and Meusemann, K. 2010. FASconCAT: Convenient handling of data matrices. Mol. Phylogenet. Evol. 56:1115-1118.

Langlois, P. A., Snelling, J., Hamilton, J. P., Bragard, C., Koebnik, R., Verdier, V., Triplett, L. R., Blom, J., Tisserat, N. A., and Leach, J. E. 2017. Characterization of the Xanthomonas translucens complex using draft genomes, comparative genomics, phylogenetic analysis, and diagnostic LAMP assays. Phytopathology 107:519-527.

Li, L., Stoeckert, C. J., Jr., and Roos, D. S. 2003. OrthoMCL: Identification of ortholog groups for eukaryotic genomes. Genome Res. 13:2178-2189.

Li, W., and Godzik, A. 2006. Cd-hit: A fast program for clustering and comparing large sets of protein or nucleotide sequences. Bioinformatics 22:1658-1659.

Li, X., Tambong, J., Yuan, K. X., Chen, W., Xu, H., Levesque, C. A., and DeBoer, S. H. 2018. Re-classification of Clavibacter michiganensis subspecies on the basis of whole-genome and multi-locus sequence analyses. Int. J. Syst. Evol. Microbiol. 68:234-240.

Li, Y., van der Lee, T. A. J., Evenhuis, A., van den Bosch, G. B. M., van Bekkum, P. J., Forch, M. G., van Gent-Pelzer, M. P. E., van Raaij, H. M. G., Jacobsen, E., Huang, S. W., Govers, F., Vleeshouwers, V. G. A. A., and Kessel, G. J. 2012. Population dynamics of Phytophthora infestans in the Netherlands reveals expansion and spread of dominant clonal lineages and virulence in sexual offspring. G3: Genes Genomes Genet. 2:1529-1540.

Louws, F. J., Bell, J., Medina-Mora, C. M., Smart, C. D., Opgenorth, D., Ishimaru, C. A., Hausbeck, M. K., de Bruijn, F. J., and Fulbright, D. W. 1998. rep-PCR-mediated genomic fingerprinting: A rapid and effective method to identify Clavibacter michiganensis. Phytopathology 88:862-868.

Louws, F. J., Rademaker, J. L. W., and de Bruijn, F. J. 1999. The three Ds of PCR-based genomic analysis of phytobacteria: Diversity, detection, and disease diagnosis. Annu. Rev. Phytopathol. 37:81-125.

Loytynoja, A., and Goldman, N. 2005. An algorithm for progressive multiple alignment of sequences with insertions. Proc. Natl. Acad. Sci. U.S.A. 102: 10557-10562.

Luo, L. X., Walters, C., Bolkan, H., Liu, X. L., and Li, J. Q. 2008. Quantification of viable cells of Clavibacter michiganensis subsp. michiganensis using a DNA binding dye and a real-time PCR assay. Plant Pathol. 57:332-337.

Mansfield, J., Genin, S., Magori, S., Citovsky, V., Sriariyanum, M., Ronald, P., Dow, M., Verdier, V., Beer, S. V., Machado, M. A., Toth, I., Salmond, G., and Foster, G. D. 2012. Top 10 plant pathogenic bacteria in molecular plant pathology. Mol. Plant Pathol. 13:614-629.

McNally, R. R., Ishimaru, C. A., and Malvick, D. K. 2016. PCR-mediated detection and quantification of the Goss's wilt pathogen Clavibacter michiganensis subsp. nebraskensis via a novel gene target. Phytopathology 106:1465-1472.

Meletzus, D., Bermphol, A., Dreier, J., and Eichenlaub, R. 1993. Evidence for plasmid-encoded virulence factors in the phytopathogenic bacterium Clavibacter michiganensis subsp. michiganensis NCPPB382. J. Bacteriol. 175:2131-2136.

Milijašević-Marčić, S., Gartemann, K.-H., Frohwitter, J., Eichenlaub, R., Todorović, B., Rekanović, E., and Potočnik, I. 2012. Characterization of Clavibacter michiganensis subsp. michiganensis strains from recent outbreaks of bacterial wilt and canker in Serbia. Eur. J. Plant Pathol. 134:697-711.

Murray, M. G., and Thompson, W. F. 1980. Rapid isolation of high molecular weight plant DNA. Nucleic Acids Res. 8:4321-4326.
Ozdemir, Z. 2009. Development of a multiplex PCR assay for the simultaneous detection of Clavibacter michiganensis subsp. michiganensis, Pseudomonas syringae pv. tomato and Xanthomonas axonopodis pv. vesicatoria using pure cultures. J. Plant Pathol. 91:495-497.

Pastrik, K. H., and Rainey, F. A. 1999. Identification and differentiation of Clavibacter michiganensis subspecies by polymerase chain reaction-based techniques. J. Phytopathol. 147:687-693.

Rambaut, A. 2012. FigTree, version 1.4.0. http://tree.bio.ed.ac.uk/software/ figtree

Santos, M. S., Cruz, L., Norskov, P., and Rasmussen, O. F. 1997. A rapid and sensitive detection of Clavibacter michiganensis subsp. michiganensis in tomato seeds by polymerase chain reaction. Seed Sci. Technol. 25:581-584.

Savory, E. A., Fuller, S. L., Weisberg, A. J., Thomas, W. J., Gordon, M. I., Stevens, D. M., Creason, A. L., Belcher, M. S., Serdani, M., Wiseman, M. S., Grunwald, N. J., Putnam, M. L., and Chang, J. H. 2017. Evolutionary transitions between beneficial and phytopathogenic Rhodococcus challenge disease management. eLife 6:e30925.

Schaad, N. W., and Frederick, R. D. 2002. Real-time PCR and its application for rapid plant disease diagnostics. Can. J. Plant Pathol. 24:250-258.

Seemann, T. 2014. Prokka: Rapid prokaryotic genome annotation. Bioinformatics 30:2068-2069.

Sen, Y., van der Wolf, J., Visser, R. G. F., and van Heusden, S. 2015. Bacterial canker of tomato: Current knowledge of detection, management, resistance, and interactions. Plant Dis. 99:4-13.

Smith, E. F. 1910. A new tomato disease of economic importance. Science 31: 794-796.

Stamatakis, A. 2006. RAxML-VI-HPC: Maximum likelihood-based phylogenetic analyses with thousands of taxa and mixed models. Bioinformatics 22:2688-2690

Tancos, M. A., Lange, H. W., and Smart, C. D. 2015. Characterizing the genetic diversity of the Clavibacter michiganensis subsp. michiganensis population in New York. Phytopathology 105:169-179.

Tatusova, T., DiCuccio, M., Badretdin, A., Chetvernin, V., Nawrocki, E. P., Zaslavsky, L., Lomsadze, A., Pruitt, K. D., Borodovsky, M., and Ostell, J. 2016. NCBI prokaryotic genome annotation pipeline. Nucleic Acids Res. 44:6614-6624

Thapa, S. P., Han, A. R., Cho, J. M., and Hur, J. H. 2013. Multiplex PCR and DNA array for the detection of Bacillus cereus, Staphylococcus aureus, Listeria monocytogenes, Escherichia coli O157:H7, and Salmonella spp. targeting virulence-related genes. Ann. Microbiol. 63:725-731.

Thapa, S. P., Miyao, E. M., Davis, R. M., and Coaker, G. 2015. Identification of QTLs controlling resistance to Pseudomonas syringae pv. tomato race 1 strains from the wild tomato, Solanum habrochaites LA1777. Theor. Appl. Genet. 128:681-692.

Thapa, S. P., Park, D. H., Wilson, C., Hur, J. H., and Lim, C. K. 2012. Multiplex PCR assay for the detection of Pantoea stewartii subsp. stewartii using species-specific genetic markers. Australas. Plant Pathol. 41: 559-564.

Thapa, S. P., Pattathil, S., Hahn, M. G., Jacques, M. A., Gilbertson, R. L., and Coaker, G. 2017. Genomic analysis of Clavibacter michiganensis reveals insight into virulence strategies and genetic diversity of a gram-positive bacterial pathogen. Mol. Plant-Microbe Interact. 30:786-802.

Vincelli, P., and Tisserat, N. 2008. Nucleic acid-based pathogen detection in applied plant pathology. Plant Dis. 92:660-669.

Yasuhara-Bell, J., and Alvarez, A. M. 2015. Seed-associated subspecies of the genus Clavibacter are clearly distinguishable from Clavibacter michiganensis subsp. michiganensis. Int. J. Syst. Evol. Microbiol. 65: 811-826.

Zaluga, J., Van Vaerenbergh, J., Stragier, P., Maes, M., and De Vos, P. 2013. Genetic diversity of non-pathogenic Clavibacter strains isolated from tomato seeds. Syst. Appl. Microbiol. 36:426-435. 